\title{
APLICAÇÃO FOLIAR DE CÁLCIO E BORO E COMPONENTES DE RENDIMENTO E QUALIDADE DE SEMENTES DE SOJA
}

\author{
BORO AND CALCIUM LEAF APPLLICATION AND YIELD COMPONENTS \\ AND PHYSIOLOGICAL QUALITY OF SOYBEAN SEEDS
}

\author{
Gilberto Antonio Peripolli Bevilaqua ${ }^{1}$ Pedro Moreira Silva Filho $^{2}$ \\ Jean Carlo Possenti ${ }^{3}$
}

RESUMO

\begin{abstract}
O objetivo deste trabalho foi avaliar o efeito de cálcio (Ca) e boro (B), aplicados em pulverização foliar, nas fases vegetativa e reprodutiva da cultura de soja (Glycine max L. Merril), cvs. FT Cometa e BR 16, nos componentes de rendimento e na qualidade fisiológica de sementes. O trabalho foi conduzido em casa-devegetação. $O$ solo usado foi um Planossolo, com as seguintes

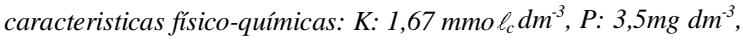
matéria orgânica: $16,6 \mathrm{~g} \mathrm{dm}^{-3}$; teores de $\mathrm{Ca}+\mathrm{Mg}: 18 \mathrm{mmo} \ell_{c} \mathrm{dm}^{-3}$ de solo, pH: 4,7 e argila: $11 \%$. As unidades experimentais foram bandejas com capacidade para $20 \mathrm{~kg}$ de solo, mantidas com umidade próxima da capacidade de campo (20\%), durante o experimento. Os tratamentos consistiram da aplicação da solução em quatro épocas: pré-floração, floração, pós-floração, pré-colheita, e com uma testemunha não tratada. A solução foi preparada com cloreto de cálcio $(0,5 \%$ de Ca) e borato de sódio $(0,25 \%$ de B), corrigido para $\mathrm{pH}$ 7,0, usando-se volume de calda de $100 \ell \mathrm{ha}^{-1}$ Os componentes de rendimento avaliados foram: número de vagens e peso de grãos /planta e número de grãos/vagem. As sementes foram avaliadas através de emergência no campo, velocidade de emergência e peso da matéria seca de plântulas. Com base nos resultados, conclui-se que: a) a aplicação de Ca e B aumentou o peso de grãos por planta; b) Ca e B não afetaram a qualidade fisiológica de sementes; c) as maiores respostas de Ca e B nos componentes de rendimento foram verificadas nas fases de floração e pós-floração.
\end{abstract}

Palavras-chave: Glycine max, peso de grãos, emergência, vigor.

\section{SUMMARY}

The purpose of this work was to evaluante the calcium $(\mathrm{Ca})$ and boron $(\mathrm{B})$ effects, throught leaf spraying, in the vegetative and reprodutive phases of soybean (Glycine max $L$. Merril), cvs. FT Cometa e BR 16, on the yield components and physiological quality of seeds. The soil used was an Planossoil, with the follow physical-chemical caracters: $K$ : $1,67 \mathrm{mmo}_{c} \mathrm{dm}^{-3}$,

\begin{abstract}
P: $3,5 \mathrm{mg} \mathrm{dm}^{-3}$, organic matter: $16,6 \mathrm{~g} \mathrm{dm}^{-3} ; \mathrm{Ca}+\mathrm{Mg}$ content: $18 \mathrm{mmo}_{\mathrm{c}} \mathrm{dm}^{3}$ of soil, $\mathrm{pH}: 4,7$ and clay: $11 \%$. The experimental units were plastic trays with capacity for $20 \mathrm{~kg}$, manteined close to the field capacity (water content 20\%) during the experiment. The treatments consisted of spraying the solution in four phases: preflowering, flowering, pos-flowering and pre-harvest. The solution was preapered with $\mathrm{CaCl}_{2}(0,5 \%$ of $\mathrm{Ca})$ and $\mathrm{Na}_{2} \mathrm{BO}_{3}(0,25 \%$ of $B)$, corrected for $\mathrm{pH} 7,0$. The volume used was $100 \ell \mathrm{ha}^{-1}$. The yield components evaluated were legumen number/plant, grain number/legumen and grain weigth/plant. The seeds was evaluated througth field emergence, speed emergence and dry matter weigth of seedlings. Based on results, the conclusions were: a) the Ca and $B$ application increased the grain weight/plant; $b)$ the $C a$ and $B$ application were not affected the physiological quality of seeds; c) the best results of $\mathrm{Ca}$ and $\mathrm{B}$ application on yield components were verify in the flowering and pos-flowering phases.
\end{abstract}

Key words: Glicine max, grain yield, emergence, vigor.

\section{INTRODUÇÃO}

Os solos de várzea, cultivados com arroz no Rio Grande do Sul, apresentam-se como importante alternativa de expansão da área de cultivo de soja no estado. No entanto, esses solos são geralmente deficientes em cálcio e boro, devido ao baixo conteúdo de matéria orgânica apresentado e às baixas doses de calcário utilizadas. Segundo LOPES (1986), os solos de várzea possuem grande potencial de produção, entretanto apresentam uma natureza físico-química bastante complexa. A alta infestação de arroz vermelho (Oryza sativa L.), em solos de várzea, freqüentemente impede a continuidade do

\footnotetext{
${ }^{1}$ Engenheiro Agrônomo, Doutor, Pesquisador, Embrapa Trigo, BR 285, km 174, CP 451, 99001-970, Passo Fundo, RS. E-mail: bevilaq@cnpt.embrapa.br. Autor para correspondência.

${ }^{2}$ Engenheiro Agrônomo, Doutor, Pesquisador, SNT - Embrapa, Ponta Grossa, PR

${ }^{3}$ Engenheiro Agrônomo, Mestre, Cooperativa Duovizinhense, Dois Vizinhos, PR.
} 
cultivo do arroz irrigado em certas áreas, levando a necessidade de identificar alternativas de rotação de culturas para minimizar o problema.

Baixos teores de matéria orgânica no solo realçam a deficiência de micronutrientes no solo como: boro (B), zinco ( $\mathrm{Zn}$ ), molibdênio (Mo) e cobre (Cu) (EMBRAPA, 1999). Segundo o mesmo trabalho, é recomendado a aplicação foliar de manganês (Mn), no caso de detecção de sua deficiência, de solução de $350 \mathrm{~g} \mathrm{ha}^{-1}$ diluido em 200 litros de água. A carência de boro é muito comum no país, particularmente em solos arenosos e pobres em matéria orgânica (MALAVOLTA, 1985).

Em situações nas quais a cultura encontrese em solo com boas características físicas e químicas, pode haver aumento de produção com adubação foliar, entretanto a soja é muito sensível a toxidez de B (ROSOLEM, 1980). Em certos casos, a adubação foliar constitui-se em importante alternativa de adubação das culturas. ROSOLEM \& MACHADO (1991), estudando a eficiência da adubação nitrogenada, via solo e via aplicação foliar na cultura do trigo, observaram que a aplicação foliar foi 34 a $62 \%$ mais eficiente em termos de resposta da planta.

$\mathrm{O}$ elemento químico $\mathrm{Ca}$, assim como o $\mathrm{B}$, são imóveis no floema e não se redistribuem na planta, assim a deficiência nutricional de ambos se apresenta em órgãos mais novos (MALAVOLTA, 1976, 1985; DEVLIN, 1975). As principais funções do Ca na planta são: atuar na formação do pectato de cálcio, presente na lamela média da parede celular e na germinação do grão de pólen e crescimento do tubo polínico. O B é importante na translocação de açúcares e na formação da parede celular. Para MALAVOLTA (1976), as folhas novas absorvem mais que as velhas. As condições ambientais como pH próximo da neutralidade e modo de aplicação, com gotas finíssimas e que atinjam a face inferior da folha, interferem na eficiência do tratamento de pulverização foliar.

Apesar da essencialidade dos micronutrientes, para os vegetais, ter sido demonstrada há bastante tempo, recentemente foi demonstrado experimentalmente o seu efeito benéfico sobre o rendimento de algumas culturas, para certas condições de solo, no Brasil (LOPES, 1986). Existem evidências do efeito benéfico da aplicação foliar de micronutrientes em certas culturas, como a soja (ROSOLEM \& BOARETTO, 1989). Para ROSOLEM et al. (1990), o cálcio atua decisivamente no número de flores e vagens abortadas em feijoeiro, e existe alta correlação negativa entre teor de Ca na planta e número de flores e vagens abortadas. Há relatos de aumento da produtividade de algumas culturas com o uso do borax e outros micronutrientes (MELLO et al., 1985).
O objetivo do trabalho foi avaliar o efeito de cálcio $(\mathrm{Ca})$ e boro $(\mathrm{B})$, aplicados em pulverização foliar, nas fases vegetativa e reprodutiva da cultura de soja, nos componentes de rendimento e na qualidade fisiológica de sementes.

\section{MATERIAL E MÉTODOS}

O trabalho foi conduzido em casa-devegetação, no Centro de Pesquisa Agropecuária de Clima Temperado (CPACT), da Embrapa, em Pelotas, RS. O solo usado foi um Planossolo Hidromórfico Eutrófico solódico epidistrófico com argila de atividade alta (Embrapa Solos, 1999). A análise de solo apresentou as seguintes características físicoquímicas: $\mathrm{K}: 1,67 \mathrm{mmo}_{\mathrm{c}} \mathrm{dm}^{-3}, \mathrm{P}: 3,5 \mathrm{mg} \mathrm{dm}^{-3}$, matéria orgânica: $16,6 \mathrm{~g} \mathrm{dm} \mathrm{dm}^{-3}$; teores de $\mathrm{Ca}+\mathrm{Mg}$ : $18 \mathrm{mmo} \ell_{\mathrm{c}} \mathrm{dm}^{-3}$ de solo, pH: 4,7 e argila: $11 \%$. Foram usadas sementes das cultivares FT Cometa e BR 16.

Foi preparada uma solução com cloreto de cálcio $(0,5 \%$ de $\mathrm{Ca})$ e borato de sódio $(0,25 \%$ de $\mathrm{B})$, com o pH corrigido para 7,0. A dose de calda utilizada foi $100 \ell \mathrm{ha}^{-1}$. As unidades experimentais foram bandejas plásticas de $65 \mathrm{~cm}$ x $20 \mathrm{~cm}$ x $20 \mathrm{~cm}$, com capacidade para $20 \mathrm{~kg}$ de solo, contendo 10 plantas, mantidas próximo à capacidade de campo (teor de água de 20\%), durante o experimento (Ledemar Carlos Vahl, comunicação pessoal). Os tratamentos consistiram da pulverização da solução em quatro épocas: 10 dias antes da floração (botões florais fechados), floração plena ( $80 \%$ das flores abertas), 15 dias após a floração (vagens com 3 a $5 \mathrm{~mm}$ ) e 30 dias após a floração (vagens com $15 \mathrm{~mm}$ ), mais uma testemunha, sem tratamento.

Foram avaliados os seguintes componentes de rendimento: a) número de vagens por planta, em que se colheram as plantas e contou-se o número de vagens; b) número de grãos por vagem, em que se debulharam as vagens e contaram-se os grãos; e c) peso de grãos por planta, em que se pesaram os grãos após 3 semanas na câmara seca a $40 \%$ de umidade relativa, ajustada para $13 \%$ de umidade.

Foi avaliada, também, a qualidade fisiológica das sementes produzidas aos 90 dias após a colheita por meio de: a) emergência no campo, aos 21 dias após a semeadura (DAS) em linhas com 50 sementes em bandeja com $8 \mathrm{~kg}$ de terra+areia; b) vigor, mediante a contagem de emergência aos 5 DAS; c) peso da matéria seca, as plântulas foram colhidas aos 21 DAS, secas em estufa a $60^{\circ} \mathrm{C}$, após foram pesadas e o resultado expresso em gramas.

O delineamento experimental utilizado foi blocos casualizados com quatro repetições. O fator época de aplicação foi analisado pelo teste de Dunnet, comparando os diversos tratamentos com a testemunha, e o fator cultivar, pelo teste de análise 
de variância, a $5 \%$ de probabilidade de erro. Os dados foram analisados pelo Sistema de Análise Estatística SANEST (ZONTA et al., 1986).

\section{RESULTADOS E DISCUSSÃO}

Na tabela 1 são apresentados os valores de teor de água, vigor e germinação das sementes das duas cultivares, onde se constata que a cv. BR-16, apresentou sementes maiores que a cv. FT Cometa, revelados pelo maior peso de mil sementes.

A aplicação foliar de Ca e B aumentou o número de vagens por planta e de grãos por vagem e o peso de sementes por planta, quando aplicados na fase de floração, na cv. BR 16 (Tabela 2). Na cv. FT Cometa, houve aumento no número de grãos por vagem na época de pós-floração, sem apresentar, no entanto, aumento do peso de sementes por planta. Resultados semelhantes foram encontrados por MARUBAYASHI $\boldsymbol{e}$ t al. (1994), em cujo trabalho o ácido bórico a $0,3 \%$, via aplicação foliar, junto com $\mathrm{Zn}$ na cova, mostrou aumento na produtividade de grãos do cafeeiro. Segundo ROSOLEM et al. (1990), existe alta correlação negativa entre teor de $\mathrm{Ca}$ na planta e número de flores e vagens abortadas o que explica também o resultado positivo do $\mathrm{Ca}$ e $\mathrm{B}$ no peso de sementes por planta.

Contrários a esses resultados, ROSOLEM et al. (1990) não detectaram resposta do feijoeiro a fontes e doses de $\mathrm{Ca}$, aplicado via foliar na fase de pré-florescimento, em termos de rendimento e seus componentes, tampouco o estado nutricional da planta foi modificado. Da mesma maneira, para BEN et al. (1993) não houve efeito benéfico dos fertilizantes foliares contendo $\mathrm{Ca}$ a $10 \%$, sozinho, ou $\mathrm{B}$ a $4,5 \%$, junto com outros micronutrientes sobre o rendimento de soja, semeada em Passo Fundo, RS, em duas épocas de semeadura. Este fato pode estar relacionado ao tipo de solo utilizado, com bom suprimento de $\mathrm{Ca}$ e $\mathrm{B}$, e às cultivares pouco responsivas.

Segundo BOARETTO et al. (1983), o cálcio é rapidamente absorvido pelas folhas do feijo-

Tabela 1 - Teor de água (TA), germinação $(\mathrm{G})$, vigor (primeira contagem de germinação) e peso de mil sementes (PMS) de duas cultivares de soja. Pelotas, RS, 1997.

\begin{tabular}{lcccc}
\hline Cultivar & TA $(\%)$ & G $(\%)$ & Vigor $(\%)$ & PMS (g) \\
\hline BR 16 & 11,2 & 88 & 88 & 161,9 \\
FT Cometa & 11,0 & 95 & 95 & 140,8 \\
\hline
\end{tabular}

eiro, após a aplicação por pulverização foliar, entretanto quantidades insignificantes são translocadas para outros órgãos da planta. Por outro lado, ROSOLEM \& BOARETTO (1989) colocam que a época de maior demanda de nutrientes pelas plantas de soja é R1 a R5. Assim, na medida em que o Ca e B não são retranslocados na planta, via floema, pode-se afirmar que a aplicação destes nutrientes deva ser feita na fase de floração ou pós-floração para haver um efeito sobre o rendimento de grãos.

As duas cultivares apresentaram resultados semelhantes para os três componentes de rendimento, exceto para maior número de vagens por planta na cv. BR 16 (Tabela 2). No entanto, esse aumento não se refletiu em maior peso de sementes por planta.

A cv. BR 16 apresentou maior rendimento em relação à FT- Cometa, conforme é observado pelo peso de sementes por planta (Tabela 2). $\mathrm{O}$ fato pode relacionar-se à produtividade maior da primeira, em relação à segunda, pois a cv. FT Cometa possui ciclo precoce e estas, geralmente, são menos produtivas que cultivares médias e tardias. A cv. BR 16 apresentou maior resposta a aplicação foliar de Ca e B em relação a cv. FT Cometa, apresentando resposta positiva no número de grãos/vagem, número de vagens e peso de sementes/planta, enquanto a cv. FT Cometa apenas no número de grãos/vagem. Isto contraria resultados de ROSOLEM (1980), no qual cultivares de soja precoces apresentam melhores respostas à adubação foliar do que às cultivares tardias.

$\mathrm{A}$ adição de $\mathrm{Ca}$ e $\mathrm{B}$ não melhorou $\mathrm{a}$ qualidade fisiológica das sementes produzidas (Tabela 3), em nenhuma das fases de aplicação. Esses resultados discordam de ROSOLEM et al. 
Tabela 3 - Efeito da pulverização foliar de Ca e de B na primeira contagem de germinação (vigor), na emergência no campo (EC) e no peso da matéria seca (PMS) de plântulas de duas cultivares de soja, cultivadas em Planossolo. Pelotas, RS, 1997

\begin{tabular}{lllllll}
\hline Época de & \multicolumn{2}{c}{ Vigor (\%) } & \multicolumn{2}{c}{ EC (\%) } & \multicolumn{2}{c}{ PMS (g) } \\
\cline { 2 - 7 } aplicação & BR 16 & FT Cometa & BR 16 & FT Cometa & BR 16 & FT Cometa \\
\hline Testemunha & 66 & 67 & 81 & 79 & 3,34 & 3,49 \\
Pré-floração & $63 \mathrm{~ns}$ & $65 \mathrm{~ns}$ & $81 \mathrm{~ns}$ & $82 \mathrm{~ns}$ & $2,70 \mathrm{~ns}$ & $4,39 \mathrm{~ns}$ \\
Floração & $75 \mathrm{~ns}$ & $81 \mathrm{~ns}$ & $90 \mathrm{~ns}$ & $86 \mathrm{~ns}$ & $3,76 \mathrm{~ns}$ & $3,97 \mathrm{~ns}$ \\
Pós-floração & $72 \mathrm{~ns}$ & $61 \mathrm{~ns}$ & $86 \mathrm{~ns}$ & $79 \mathrm{~ns}$ & $3,29 \mathrm{~ns}$ & $4,39 \mathrm{~ns}$ \\
Pré-colheita & $71 \mathrm{~ns}$ & $63 \mathrm{~ns}$ & $78 \mathrm{~ns}$ & $86 \mathrm{~ns}$ & $4,18 \mathrm{~ns}$ & $4,18 \mathrm{~ns}$ \\
Média & $71 \mathrm{~ns}$ & 63 & $80 \mathrm{~ns}$ & 80 & $3,72^{* *}$ & 4,08 \\
\multicolumn{2}{c}{ CV\% } & \multicolumn{2}{c}{8,8} & \multicolumn{2}{c}{8,5} & \multicolumn{2}{c}{20,4} \\
\hline
\end{tabular}

* indica diferença estatística entre época de aplicação, pelo teste de Dunnet, ao nível de $5 \%$ de probabilidade de erro

** indica diferença estatística entre as médias de cultivares pelo teste de análise de variância ao nível de $5 \%$ de probabilidade de erro

ns: efeito não significativo.

(1990), que verificaram melhoria na qualidade fisiológica das sementes do feijoeiro em função das doses de $\mathrm{Ca}$ aplicado. Estudos posteriores relacionando o efeito de dano mecânico sobre as sementes produzidas seriam convenientes, visto que o cálcio aumenta a resistência do tegumento das sementes e as mesmas são produzidas em casa-devegetação, isentas de dano mecânico.

A cv. FT Cometa apresentou maior peso da matéria seca de plântulas que a cv. BR 16 (Tabela 3 ), embora a primeira apresente sementes menores. Este fato pode estar relacionado à aplicação do Ca e B. Segundo POPINIGIS (1985), sementes maiores possuem maior germinação e vigor em relação a sementes menores. De outro lado, EDWARDS \& HARTWIG (1971) apresentaram dados em que sementes pequenas e médias tiveram germinação mais rápida e maior desenvolvimento de raízes do que sementes maiores.

\section{CONCLUSÃO}

A aplicação via foliar de cálcio e boro aumentou o peso de grãos por planta de soja em solos de várzea; o Ca e B não afetou a qualidade fisiológica das sementes produzidas; as maiores respostas de $\mathrm{Ca}$ e $\mathrm{B}$ nos componentes de rendimento foram verificadas nas fases de floração e pósfloração.

\section{REFERÊNCIAS BIBLIOGRÁFICAS}

BEN, J.R.; POTTKER, D.; MEDEIROS, L.A. Avaliação de ferilizantes foliares para a soja. In: REUNIÃO DE PESQUISA DE SOJA DA REGIÃO SUL, 21, 1993. Santa
Rosa. Soja; Resultados de Pesquisa 19921993. Santa Rosa : Cooperativa Mista Missões. 199p. (Embrapa-CNPT. Documentos, 9).

BOARETTO, A.E.; DAGHLIAN, C.; MURAOKA $\mathrm{T}$., et al. Absorção foliar e translocação de cálcio ( ${ }^{45} \mathrm{Ca}$ ) pelo feijoeiro. Científica, São Paulo, v.11, p. 227-231. 1983.

DEVLIN, R. Plant physiology. New York: John Willey \& Sons, 1975. 600p.

EDWARDS, C.J.; HARTWIG, E.E. Effect of seed size upon rate of germination in soybeans. Agronomy Journal, v.63, p.429430. 1971.

EMBRAPA. Centro Nacional de Pesquisa de Soja. Recomendações técnicas para a cultura de soja no Paraná 1999/2000. Londrina, 1999. 236p. (Embrapa Soja. Documento, 131).

EMBRAPA. Centro Nacional de Pesquisa de Solos. Sistema brasileiro de classificação de solos. Brasília : Embrapa Produção de Informação; Rio de Janeiro: Embrapa Solos, 1999. 412p.

LOPES, A.S. Micronutrientes nos solos e culturas brasileiras. In: SILVA, M.C. (Coordenador). Anais do Seminário Fósforo, cálcio, magnésio, enxofre e micronutrientes - Situação atual e perspectivas na Agricultura. 2 ed. São Paulo : MANAH S/A, 1986. p.110-141.

MAlavolta, E. Manual de química agrícola. São Paulo : Agronômica Ceres, 1976. 528p.

MALAVOLTA, E. Nutrição de plantas. In: FERRI, M.G. (org.) Fisiologia vegetal. São Paulo : EDUSP, 1985. Vol.1, 400p.

MARUBAYASHI, O.M.; PEDROSO, P.A.C.; VITTI, G.C., $\boldsymbol{e}$ t al. Efeito de fontes e formas de aplicação de boro e zinco na cultura do cafeeiro. Científica, São Paulo, v.22, p.289-299. 1994.

MELLO, F.A.F.; BRASIL SOBRINHO, M.O.C.; ARZOLLA, S., et al. Fertilidade do solo. 3ed. São Paulo : Nobel, 1985. 400p.

POPINIGIS, F. Fisiologia da semente. Brasília : AGIPLAN, 1985. 289p.

ROSOLEM, C.A.; BOARETTO, A.E. A adubação foliar em soja. In: BOARETTO, A.E.; ROSOLEM, C.A. Adubação foliar. Campinas, SP : Fundação Cargill. 1989. 500p.

ROSOLEM, C.A.; BOARETTO, A.E.; NAKAGAWA, J. Adubação foliar do feijoeiro. VIII. Fontes e doses de cálcio. Científica, São Paulo, v.18, p.81-86, 1990.

ROSOLEM, C.A.; MACHADO, J.R. Eficiência da cobertura nitrogenada via solo e foliar em trigo. Científica, São Paulo, v.19, p.9-14. 1991.

ROSOLEM, C.A. Nutrição mineral e adubação de soja Piracicaba : Instituto da potassa, 1980. 80p. (Boletim Técnico, 6)

ZONTA, E.P.; MACHADO A.A. Sistema de análise estatística para micro-computadores - SANEST. Pelotas: UFPEL/Instituto de Física e Matemática, 1986. 190p. 